\title{
ChemComm
}

Check for updates

Cite this: Chem. Commun., 2017 53, 10463

Received 21st July 2017

Accepted 4th September 2017

DOI: $10.1039 / c 7 c c 05672 a$

rsc.li/chemcomm

\section{Thiol-ene/oxidation tandem reaction under visible light photocatalysis: synthesis of alkyl sulfoxides $\dagger$}

\author{
Andrea Guerrero-Corella, (D) a Ana María Martinez-Gualda, (D) a Fereshteh Ahmadi, \\ Enrique Ming, ${ }^{a}$ Alberto Fraile (iD *ab and José Alemán iD *ab
}

The photocatalyzed synthesis of sulfoxides from alkenes and thiols has been carried out using Eosin Y. This is a metal-free method which uses a low catalyst loading, atmospheric oxygen as the oxidant, and visible light conditions (green light). A mechanism has been proposed that is consistent with the experimental results.

The radical addition of thiols to olefins was described by Posner in $1905,{ }^{1}$ and has since emerged as one of the most direct methods for the construction of carbon-sulfur bonds. The thiol-ene reaction has attracted much scientific attention in recent years, ${ }^{2}$ particularly in the fields of polymers, materials and drug design. In the latter case, there are a wide variety of sulfur-containing pharmaceuticals and natural products e.g. zantac and romidepsin. ${ }^{3}$ In addition, this has increased its importance as ligands and chiral auxiliaries in synthetic chemistry. ${ }^{4}$ The thiol-ene coupling fulfills the requirements of the 'click-chemistry' concept ${ }^{5}$ due to the atom economy, efficiency and regioselectivity of the process. In this reaction, the anti-Markovnikov radical addition of the S-H bond occurs to an alkene (eqn (a), Scheme 1). This reaction can be initiated by thermal activation, using a radical initiator or by direct irradiation with UV light. However, this procedure often results in a low yield due to uncontrollable radical routes and the formation of different by-products. In the last years, visible light photoredox catalysis has emerged as a new powerful tool for the construction of organic molecules, using LEDs and domestic light bulbs which are cheaper and easier to handle than UV reactors. ${ }^{6}$ In 2012, Yoon's group demonstrated that thiol-ene reactions can occur by photo-redox using ruthenium catalysts with visible light. ${ }^{7}$ Two years later, Stephenson et al. proposed a mechanism in which a catalytic initiation and propagation of

\footnotetext{
${ }^{a}$ Departamento de Química Orgánica (Módulo 1), Facultad de Ciencias, Universidad Autónoma de Madrid, 28049, Madrid, Spain.

E-mail: jose.aleman@uam.es; Web: www.uam.es/jose.aleman

${ }^{b}$ Institute for Advanced Research in Chemical Sciences (IAdChem),

Universidad Autónoma de Madrid, 28049, Madrid, Spain

$\dagger$ Electronic supplementary information (ESI) available. See DOI: 10.1039/c7cc05672a
}

(a) Photocatalytic Ene Reaction

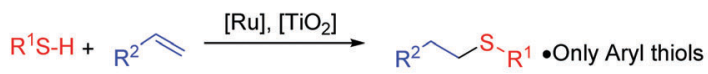

(b) Photocatalytic Oxidation

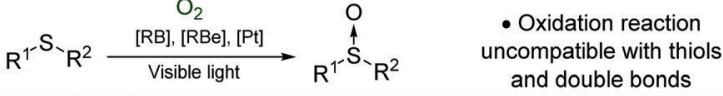

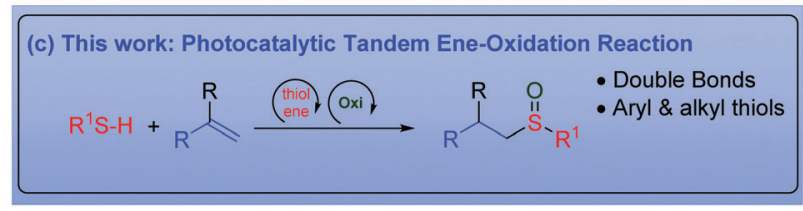

Scheme 1 Previous reactions and tandem reaction of this work.

the reaction occurs in synergistic cycles. ${ }^{8}$ In this case bromotrichloromethane is reduced by initiation, generating the trichloromethyl radical, which promotes the addition and propagation reactions. ${ }^{8}$ More recently, semiconductor metal oxides $\left(\mathrm{TiO}_{2}\right)^{9}$ and phenylglyoxylic acid ${ }^{10}$ have also been employed in the thiol-ene addition. All of these methods are exclusively used for the synthesis of thioethers by thiol-ene reaction.

On the other hand, the sulfinyl group can be found in several natural and pharmaceutical products such as esomeprazole, alliin and armodafinil. In addition, the sulfinyl group has been used as a chiral auxiliary ${ }^{11}$ or in many other reactions such as the Pummerer and Mislow-Evans rearrangements. ${ }^{12}$ The most traditional way for the synthesis of sulfoxides is the oxidation of sulfur derivatives. ${ }^{13}$ This oxidation is typically carried out using peroxides or peracids. However, the over-oxidation to sulfones and the safety aspects related to their use ( $m$-CPBA, peracetic acid) are the main drawbacks associated with industrial processes. The oxidation of sulfides using atmospheric oxygen has proved to be a safer alternative (eqn (b), Scheme 1). This has been achieved using different photocatalysts. ${ }^{14}$ Rose Bengal, ${ }^{14 a}$ tetra-O-acetyl-riboflavin, ${ }^{14 b}$ or the platinum complex developed by our group, ${ }^{14 c}$ have showed to be good alternatives for this oxidation. Consequently, for the synthesis of alkylsulfoxide derivatives, a two-step process with two different catalytic systems is necessary. Therefore, two 
consecutive reactions are required as well as the isolation and the purification of the intermediates. ${ }^{15}$

Tandem reactions are considered to be a good alternative to economize the number of steps in the synthesis of products, by avoiding intermediate purification processes. ${ }^{16}$ Even though in the field of organocatalysis and metal-catalyzed reactions, tandem reactions have been widely developed, the number of publications relating to tandem processes in the photocatalytic field are scarce. ${ }^{17}$ Therefore, we considered whether it would be possible to carry out the tandem thiol-ene reaction and direct oxidation to sulfoxides, using a single photocatalyst and visible light (eqn (c), Scheme 1). However, in order to make both catalytic cycles (thiol-ene and oxidation) compatible, certain requirements must be met: (i) the formation of disulfides in the presence of oxygen should be avoided; ${ }^{18}$ (ii) the oxidation of the double bond with oxygen species should be eliminated (aldehyde formation) $)^{19}$ and (iii) the over-oxidation to sulfone must be controlled. ${ }^{13}$ In this work, we have developed the thiol-ene/ oxidation tandem reaction, starting from alkenes. In addition, a plausible mechanism based on different mechanistic proofs is presented.

With the previous hypothesis, we started the screening reaction conditions by the addition of thiol 2a to styrene 1a in the presence of different photocatalysts using $\mathrm{CH}_{2} \mathrm{Cl}_{2}$ as solvent in an open-air vial (Table 1). Different light irradiation was chosen dependent on the absorption of the photocatalysts. Different iridium catalysts (3a-3d) enabled us to obtain as the major product the desired compound $4 \mathrm{a}$, but they always resulted in a certain amount of the sulfur compound 5a and aldehyde $\mathbf{6 a}$ (entries 1-4). Other photocatalysts such as $\mathbf{3 e}$, rhodamine $\mathbf{3 f}$, led to a mixture of products, and Rose Bengal $\mathbf{3 g}$ did not evolve to the final oxidation after 36 hours. However, the inexpensive Eosin $\mathrm{Y}$ produced a full conversion in a very selective manner and yielded sulfoxide $\mathbf{4 a}$ (entry 8) exclusively. Other solvents or lower catalyst loading also led to the final product $\mathbf{4 a}$, but with a lower selectivity (entries 10-13). The absence of Eosin Y did not afford any conversion (entry 14) in DCM or other solvents and blue light (see ESI $\dagger$ for details). With the best conditions ascertained (entry 8), we continued with different thiols (Scheme 2) and different double bonds (Schemes 3 and 4).

The reaction of phenyl derivatives, containing electrondonating groups, allowed the final products $\mathbf{4 b}$ and $\mathbf{4 c}$ with lower yield than the benzyl group (4a) due to the formation of different byproducts, whereas the electron-withdrawing groups (EWGs) achieved a better yield (4d) (Scheme 2). The alkyl thiols were also compatible with the tandem reaction (4e), even in the case of the bulkiest of them (4f). Different EWGs and electrondonating groups (EDGs) at the double bond were tolerated under these reaction conditions (Scheme 3). The use of a methoxy group or $\mathrm{CF}_{3}$ at the phenyl derivative produced $4 \mathrm{~g}$ and $4 \mathrm{~h}$ in good yields. Interestingly, the presence of those groups sensitive to radical conditions, such as the nitro group (1i) or the bromine atom $(\mathbf{1} \mathbf{j})$, allowed the synthesis of sulfoxides $4 \mathbf{i}$ and $4 \mathbf{j}$ in good yields. However, the presence of a bulkier substituent such as the naphthyl group (1k) gave a moderate yield. The reaction also worked with trisubstituted double bonds
Table 1 Screening reaction conditions for the addition of $2 \mathbf{a}$ to $1 \mathbf{a}$ in the presence of oxygen $^{a}$

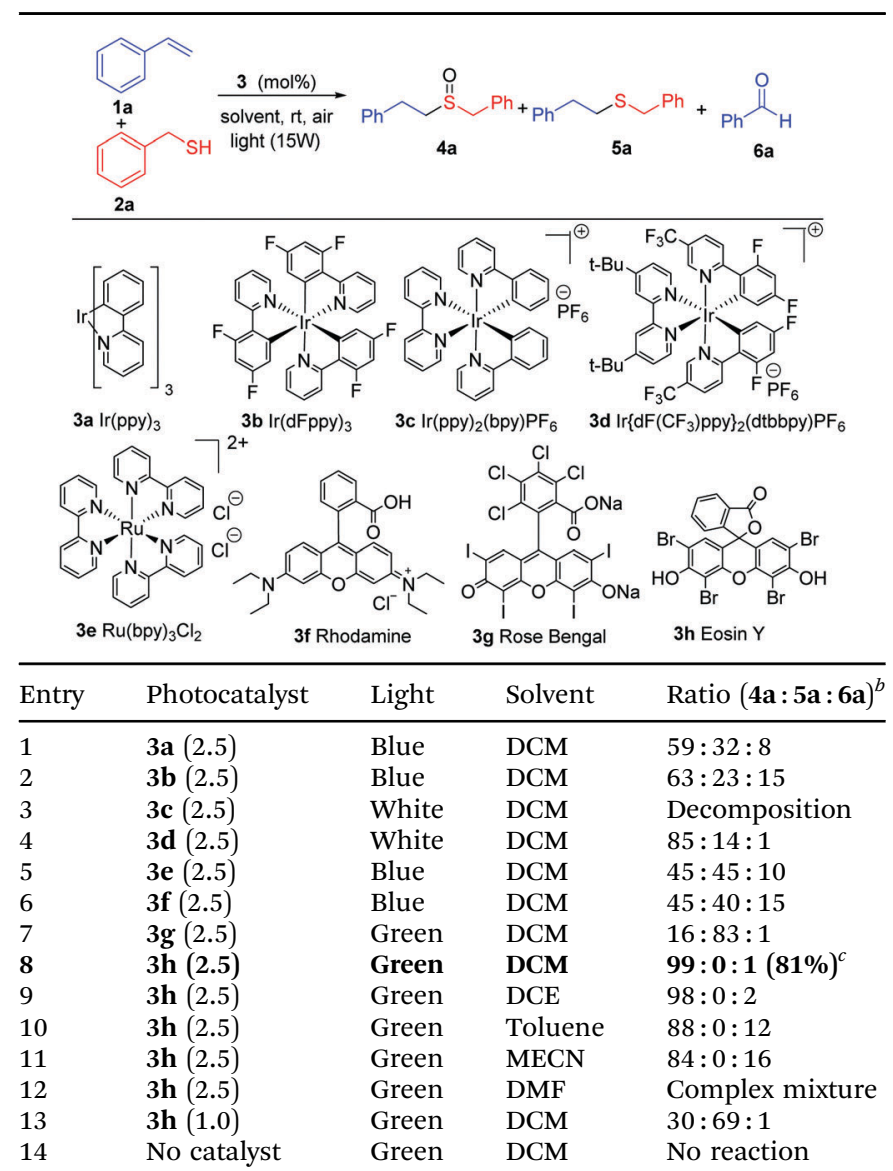

${ }^{a}$ Reactions were performed in $0.1 \mathrm{mmol}$ scale of $1 \mathrm{a}$ in $0.360 \mathrm{~mL}$ of the indicated solvent after 36 h. ${ }^{b}$ Determined by ${ }^{1} \mathrm{H}$-NMR. ${ }^{c}$ Isolated yield after flash chromatography.

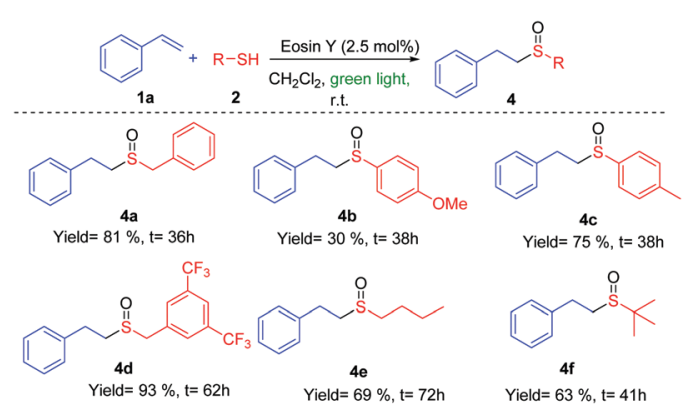

Scheme 2 Reactions of styrene 1a with different thiols 2

from moderate to good yields with $\alpha$-methyl (4l), $\alpha$-phenyl (4m) and $\beta$-methyl (4n) substituents. The reaction with oct-1-ene did not work.

The importance of the nitrogen atom in the pharmaceutical industry is reflected by the large number of products containing nitrogen with biological activity. ${ }^{20}$ Therefore, the inclusion of a nitrogen atom in these styrene derivatives would increase the broad spectrum of this methodology. We started using orthovinylamino substituted derivatives 7 . After some trials with 


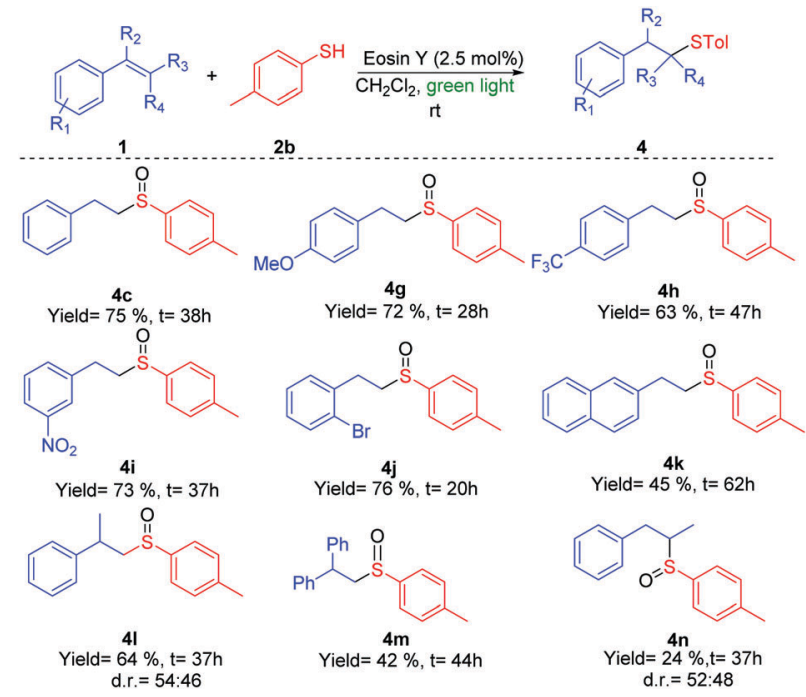

Scheme 3 Reactions of different double bonds $\mathbf{1}$ with thiol $\mathbf{2} \mathbf{b}$.

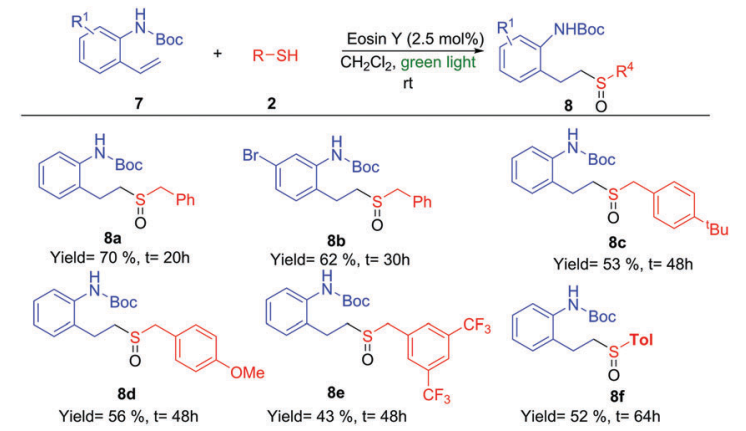

Scheme 4 Sulfoxidation of vinyl-amino derivatives 7.

different protecting groups (see ESI $\dagger$ ), we found that the use of the Boc group was the most appropriate. The use of $7 \mathbf{a}$ in optimal reaction conditions resulted in the synthesis of the amino-sulfoxide derivative 8a in a good yield after 20 hours (Scheme 4). The bromo substituent (8b) and other benzyl derivatives (8c, $8 \mathbf{d}$ and $\mathbf{8 e}$ ) were also tolerated but with a slightly lower isolated yields. The use of an aromatic group (Tol, 7f) worked with a $52 \%$ yield. As example of the potential of this methodology, we carried out one transformation to yield sevenmembered rings (Scheme 5). Compound 8a was placed under Pummerer reaction conditions, in which the more acidic benzylic position was prone to be functionalized, giving the cyclized product $(\mathbf{9})$ with $71 \%$ yield.

In order to propose a plausible mechanism for the reaction, different studies were carried out. Firstly, we performed two independent reactions to ensure that the two individual steps

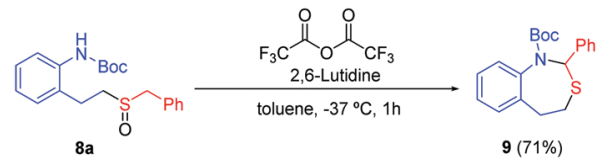

Scheme 5 Pummerer reaction over the sulfoxide $\mathbf{8 a}$. (a)

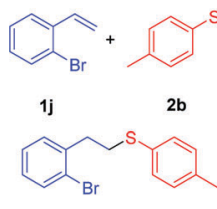

$11 \mathrm{j}$

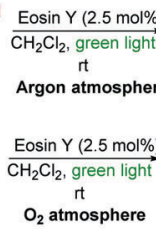

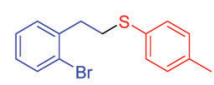

11j, Yield $=80 \%, 4 \mathrm{~h}$

4 j, Yield $=76 \%, 22 \mathrm{~h}$

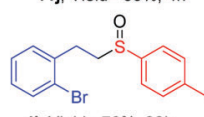

Scheme 6 Reactions of ene-addition and oxidation of compounds $1 \mathbf{j}$ and $\mathbf{1 1 j}$.

of the tandem reaction (thiol-ene reaction and oxidation) were taking place. In the absence of oxygen the thiol-ene reaction was stopped and no oxidized product $\mathbf{4} \mathbf{j}$ was observed, giving the sulfur product 11j in good yield (eqn (a), Scheme 6). In addition, when product $\mathbf{1 1} \mathbf{j}$ was placed under the same reaction conditions in the presence of oxygen, the oxidation gave the sulfoxide $\mathbf{4 j}$ in good yield. Then, Stern-Volmer fluorescence quenching studies with thiol $\mathbf{2 b}$ and the alkene $\mathbf{1 j}$ were carried out (see ESI $\dagger$ ). ${ }^{21}$ This experiment makes possible to determine if a reaction between the excited state of the $\mathrm{EY}^{*}$ and one or more substrates occur. The fluorescence of $\mathrm{EY}^{*}$ was quenched in the presence of the thiol (see ESI $\dagger$ ). Therefore, the photooxidation of the thiol by EY is thermodynamically favorable and it should be the first step in our reaction.

Once the first stage of the reaction had been determined, the next study consisted of measuring the quantum yield in the addition of thiols to the double bond. ${ }^{21,22}$ This indicates the relationship between the absorbed photons and the emitted photons. If the result is larger than one this means that a chain propagation mechanism is taking place because each mole of photons absorbed gives rise to more than one mole of product. On the other hand, if the result is less than one, this means that it is a light dependent process, although a chain propagation process cannot be eliminated. The quantum yield measured for this thiol-ene reaction was 5.8, pointing to a chain propagation mechanism. $^{22}$

For the second reaction, the oxidation step, two mechanisms are proposed for the oxidation of the sulfur atom. The first consists of a process of energy transfer to form singlet oxygen, and the second involves the transfer of an electron to form the superoxide radical anion. ${ }^{23}$ The discrimination between these two pathways can be demonstrated by indirect studies to determine which is the predominant one (see Table SI-2 in ESI $\dagger$ ). The addition of DABCO, which acts as quencher of ${ }^{1} \mathrm{O}_{2},{ }^{23,24}$ almost completely inhibits the oxidation reaction (conversion $=14 \%$ ). Interestingly, benzoquinone, which acts as scavenger of the superoxide radical anion, ${ }^{23}$ did not significantly change the final conversion (87\%), indicating that the formation of this radical derivative is not taking place. The iodine test ${ }^{25}$ did not produce the blue dark colour indicative of the formation of peroxide radical species. It is well known that oxidations via singlet oxygen can be accelerated using deuterated solvents, ${ }^{26}$ and this was observed when the reaction was performed in $\mathrm{MeOH}$ (conversion $=60 \%, 3 \mathrm{~h}$ ) and in $\mathrm{CD}_{3} \mathrm{OD}$ (conversion $=95 \%, 3 \mathrm{~h}$, see the kinetic profile in ESI $\dagger$ ). The quantum yield was also calculated for this process. We found a $\Phi=0.003$, showing that it is a light dependent process (see ESI, $\dagger$ ). ${ }^{27}$ To confirm this hypothesis the reaction was 


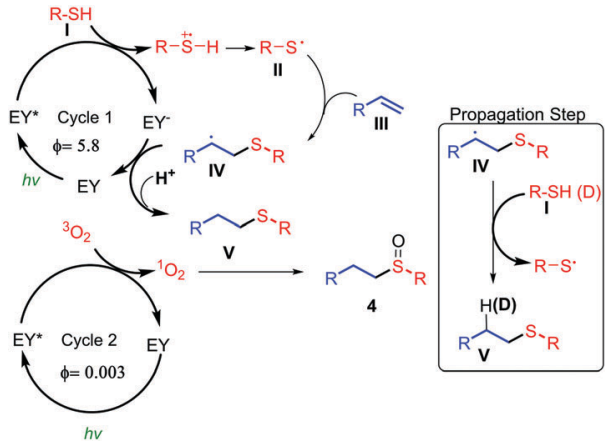

Fig. 1 Plausible mechanism based on different mechanism observations.

carried out both in the presence, and the absence of light (see ESI $\dagger$ ). The results indicated that the product formation only occurred during the periods of visible light irradiation, therefore the process is light dependent. These mechanistic proofs point to the following proposal (Fig. 1). Firstly, the EY is excited when irradiated with green light from the ground state to the triplet excited state $(E=1.91 \mathrm{eV}) .{ }^{6 c, 28}$ The photoexcited catalyst $\left(\mathrm{EY}^{*}\right.$, $E_{1 / 2}=+0.83 \mathrm{~V} v s$. SCE (saturated calomel electrode) ${ }^{6 c, 28}$ ) oxidises the thiol I, which acts as a donor via a hydrogen atom transfer process $(\mathrm{HAT})^{29}\left(E_{1 / 2}=+0.45 \mathrm{~V}\right.$ vs. SCE), ${ }^{30}$ generating a thiyl radical II. Then, alkene III reacts with the thiyl radical to form IV. This latter radical (IV) can be reduced by the oxidized EY to yield the final thioether $\mathbf{V}$, recovering the initial photocatalyst (EY). A mechanism of chain propagation is also possible according to the quantum yield $(\Phi=5.8)$ which was measured for this reaction (eqn (a), Scheme 6). Therefore, in this propagation mechanism, the radical IV can be reduced via a HAT process ${ }^{29}$ by an electron and a proton from the thiol I to form $\mathbf{V}$ (right, Fig. 1). In fact, we have used a deuterated thiol (TolSD) which has been incorporated to the final product $\mathrm{D}-\mathrm{V}\left(\mathrm{R}=o-\mathrm{Br}-\mathrm{C}_{6} \mathrm{H}_{4}\right)$ in an anti-Markovnikov manner (Fig. 1 and ESI $\dagger$ ). In the second oxidation cycle the Eosin $\mathrm{Y}$ is excited to the triplet state, and by means of an energy transfer mechanism, results in the formation of singlet oxygen ${ }^{31}$ which can react with the thioether $\mathbf{V}$ to give the final sulfoxide 4 . This mechanism is possible because the activation energy of singlet oxygen is $0.95 \mathrm{eV},{ }^{31 a, 32}$ which indicates that the energy transfer of the excited EY $\left(1.91 \mathrm{eV}^{6 c, 28}\right)$ is thermodynamically flexible.

In conclusion, the first photo-catalyzed synthesis of sulfoxides from alkenes and thiols was carried out using Eosin Y, which has been shown to be the best catalyst.

Spanish Government (CTQ2015-64561-R) and the ERC Council (ERC-CG, contract number: 647550) are acknowledged.

\section{Conflicts of interest}

There are no conflicts to declare.

\section{Notes and references}

1 T. Posner, Ber. Dtsch. Chem. Ges., 1905, 38, 646.
2 (a) J. Xu and C. Boyer, Macromolecules, 2015, 48, 520; (b) A. B. Lowe, Polym. Chem., 2014, 5, 4820; (c) A. B. Lowe, Polymer, 2014, 55, 5517.

3 M. Feng, B. Tang, S. H. Liang and X. Jiang, Curr. Top. Med. Chem., 2016, 16, 1200.

4 H. Pellissier, Chiral Sulfur Ligands, The Royal Society of Chemistry, 2009.

5 H. C. Kolb, M. G. Finn and K. B. Sharpless, Angew. Chem., Int. Ed., 2001, 40, 2004.

6 For some selected reviews in photocatalysis, see: (a) C. Prier, D. Rankic and D. W. C. MacMillan, Chem. Rev., 2013, 113, 5322; (b) J. M. R. Narayanam and C. R. J. Stephenson, Chem. Soc. Rev., 2011, 40, 102; (c) N. A. Romero and D. A. Nicewicz, Chem. Rev., 2016, 116, 10075 .

7 E. L. Tyson, M. S. Ament and T. P. Yoon, J. Org. Chem., 2013, 78, 2046.

8 M. H. Keylor, J. E. Park, C.-J. Wallentin and C. R. J. Stephenson, Tetrahedron, 2014, 70, 4264.

9 V. T. Bhat, P. A. Duspara, S. Seo, N. S. B. Abu Bakar and M. F. Greaney, Chem. Commun., 2015, 51, 4383.

10 D. Limnios and C. G. Kokotos, Adv. Synth. Catal., 2017, 359, 323.

11 B. M. Trost and M. Rao, Angew. Chem., Int. Ed., 2015, 54, 5026.

12 For Pummerer reaction, see: S. K. Bur and A. Padwa, Chem. Rev., 2004, 104, 2401.

13 (a) C. M. Rayner, Contemp. Org. Synth., 1995, 2, 409; (b) M. Madesclaire, Tetrahedron, 1986, 42, 5459.

14 (a) X. Gu, X. Li, Y. Chai, Q. Yang, P. Li and Y. Yao, Green Chem., 2013, 15, 357; (b) J. Dadová, E. Svobodová, M. Sikorski, B. König and R. Cibulka, ChemCatChem, 2012, 4, 620; (c) A. Casado-Sanchez, R. Gomez-Ballesteros, F. Tato, F. J. Soriano, G. Pascual-Coca, S. Cabrera and J. Aleman, Chem. Commun., 2016, 52, 9137.

15 The synthesis of $\beta$-ketosulfoxides, starting from double bond and thiols, was recently reported. However, our and other external group, were not able to replicate these results, obtaining always starting material and small amount of sulfoxides 4. (a) See: T. Keshari, V. K. Yadav, V. Srivastava and L. D. S. Yadav, Green Chem., 2014, 16, 3986. For a recent related work, see: (b) H. Cui, W. Wei, D. Yang, Y. Zhang, H. Zhao, L. Wang and H. Wang, Green Chem., 2017, 19, 3520.

16 (a) W. Zhao and F.-E. Chen, Curr. Org. Synth., 2012, 9, 873; (b) B. Ganem, Acc. Chem. Res., 2009, 42, 463; (c) D. J. Ramon and M. Yus, Angew. Chem., Int. Ed., 2005, 44, 1602.

17 See e.g. (a) J.-R. Chen, D.-M. Yan, Q. Wei and W.-J. Xiao, ChemPhotoChem, 2017, 1, 148; (b) B. Hu, W. Dong, Z. Feng, X. Gao, H. Gao, X. Xie and Z. Zhang, Asian J. Org. Chem., 2016, 5, 1467; (c) S. Bloom, D. D. Bume, C. R. Pitts and T. Lectka, Chem. - Eur. J., 2015, 21, 8060; (d) S. Jana, A. Verma, R. Kadu and S. Kumar, Chem. Sci., 2017, 8, 6633; (e) S. K. Pagire and O. Reiser, Green Chem., 2017, 19, 1721; $(f)$ D. Alpers, M. Gallhof, C. B. W. Starka and M. Brasholz, Chem. Commun., 2016, 52, 1025.

18 A. Talla, B. Driessen, N. J. W. Straathof, L.-G. Milroy, L. Brunsveld, V. Hessel and T. Noël, Adv. Synth. Catal., 2015, 357, 2180.

19 Y. Deng, X.-J. Wei, H. Wang, Y. Sun, T. Noël and X. Wang, Angew. Chem., Int. Ed., 2017, 56, 832.

20 A. S. Franklin and L. E. Overman, Chem. Rev., 1996, 96, 505.

21 D. M. Arias-Rotondo and J. K. McCusker, Chem. Soc. Rev., 2016, 45, 5803.

22 M. A. Cismesia and T. P. Yoon, Chem. Sci., 2015, 6, 5426.

23 S. M. Bonesi, I. Manet, M. Freccero, M. Fagnoni and A. Albini, Chem. - Eur. J., 2006, 12, 4844.

24 C. Ouannes and T. Wilson, J. Am. Chem. Soc., 1968, 90, 6527.

25 G. K. Fekarurhobo, S. S. Angaye and F. G. Obomanu, J. Emerging Trends Eng. Appl. Sci., 2013, 4, 394.

26 R. Lechner, S. Kummel and B. König, Photochem. Photobiol. Sci., 2010, 9, 1367.

27 The overall quantum yield was 0.006 (see ESI, $\uparrow$ ).

28 D. P. Hari and B. König, Chem. Commun., 2014, 50, 6688.

29 L. Capaldo and D. Ravelli, Eur. J. Org. Chem., 2017, 2056.

30 F. G. Bordwell, X.-M. Zhang, A. V. Satish and J.-P. Cheng, J. Am. Chem. Soc., 1994, 116, 6605.

31 (a) M. C. DeRosa and R. J. Crutchley, Coord. Chem. Rev., 2002, 233-234, 351; (b) J. Zhang, L. Wang, Q. Liu, Z. Yang and Y. Huang, Chem. Commun., 2013, 49, 11662.

32 E. Baciocchi, T. Del Giacco, F. Elisei, M. F. Gerini, M. Guerra, A. Lapi and P. Liberali, J. Am. Chem. Soc., 2003, 125, 16444. 